\title{
Prediction of Horizontal Axis Wind Turbine Rotor Performance: Bond Graph Approach
}

\author{
Naima Jouilel $^{1,{ }^{*}}$, Mohammed Radouani ${ }^{1}$ and Benaissa El Fahime ${ }^{1}$ \\ ${ }^{1}$ ENSAM Meknes, Mechanical Department, Moulay Ismail University, Morocco
}

\begin{abstract}
Modeling wind energy conversion systems is a difficult task that requires the use of a unified language gathering all aspect of energies involved such as kinetic energy, mechanical energy, and electrical energy. Bond Graph methodology is an appropriate tool to analyze wind turbine dynamic behavior since the whole system is modelled in the same frame. Herein, a methodology for HAWT's rotor modeling is proposed based on Bond Graph, aerodynamic laws and Rayleigh Beam theory. It takes into consideration the profile, chord, and twist change along the blade. The model is validated using 20-Sim software and then compared to other models from literature. Simulation results show a better value of power coefficient in comparison with works using the same tools.
\end{abstract}

\section{Introduction}

Wind energy is extracted from the kinetic energy available in the wind via a conversion system which should be characterized by low environmental impact, low investment, and high yield power generation. This category of energy has recently experienced significant growth and is widely seen as a potential alternative to fight against the greenhouse effect. Many architectures were developed to extract energy from wind. Horizontal Axis Wind Turbine (HAWT) has demonstrated to be a transcendent tool in extracting the energy from wind and is characterized by a higher energy efficiency, less sensitiveness to off-design conditions, and more mechanical stability compared with Vertical Axis Wind Turbine (VAWT). Figure 1 shows HAWT's main subsystems in term of BG words.

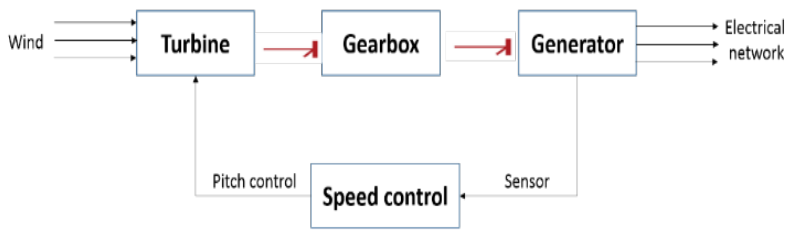

Figure 1. HAWT's main subsystems

The increase in wind generation remains limited. In fact, the maximum power that can be extracted is $60 \%$ due to Betz limit CP [1]. The fundamental equation (1) was first introduced by the German engineer Albert Betz in 1919 and published in his book "Wind Energy and its Extraction through Wind Mills" in 1926. The developed theory applies to both horizontal and vertical axis wind turbines.

$$
\mathrm{C}_{\mathrm{P}}=4 \mathrm{a}(1-\mathrm{a})
$$

Several works have been conducted to develop wind turbines with performance that greatly approximate this limit [2-6], some of the studies refer to rotor dimensioning. In [7], bond graph model of wind turbine blade was performed using Rayleigh beam theory. In [8], bond graph model of wind turbine system: rotor, gearbox, and generator linked to the network was presented. Those models neglect some specificities of blade complex geometry. The aim of our work is to establish a detailed bond graph model of wind turbine blade considering profile, twist, and chord change along the blade in order to evaluate its efficiency. The proposed model has twofold objectives:

$>$ Understand the rotor dynamic behavior for design purposes with regard to the numerous geometric specificities.

Allow changes in introduced parameters to seek high power efficiency.

This paper is organized as follow: the second section introduces Bond Graph formalism used in this study and the main steps for HAWT's modeling proposed methodology. In the third section, the method presented in [9] is exploited for rotor geometric dimensioning and the blade element momentum (BEM) is used to establish aerodynamic model. The last section presents the proposed BG model for wind turbine rotor and a verification using 20-Sim software, results will be compared with data from literature for $750 \mathrm{KW}$ wind turbine.

\section{BOND GRAPH FORMALISM FOR DESIGN MODELING}

"Corresponding author: naima.jouilel@gmail.com 


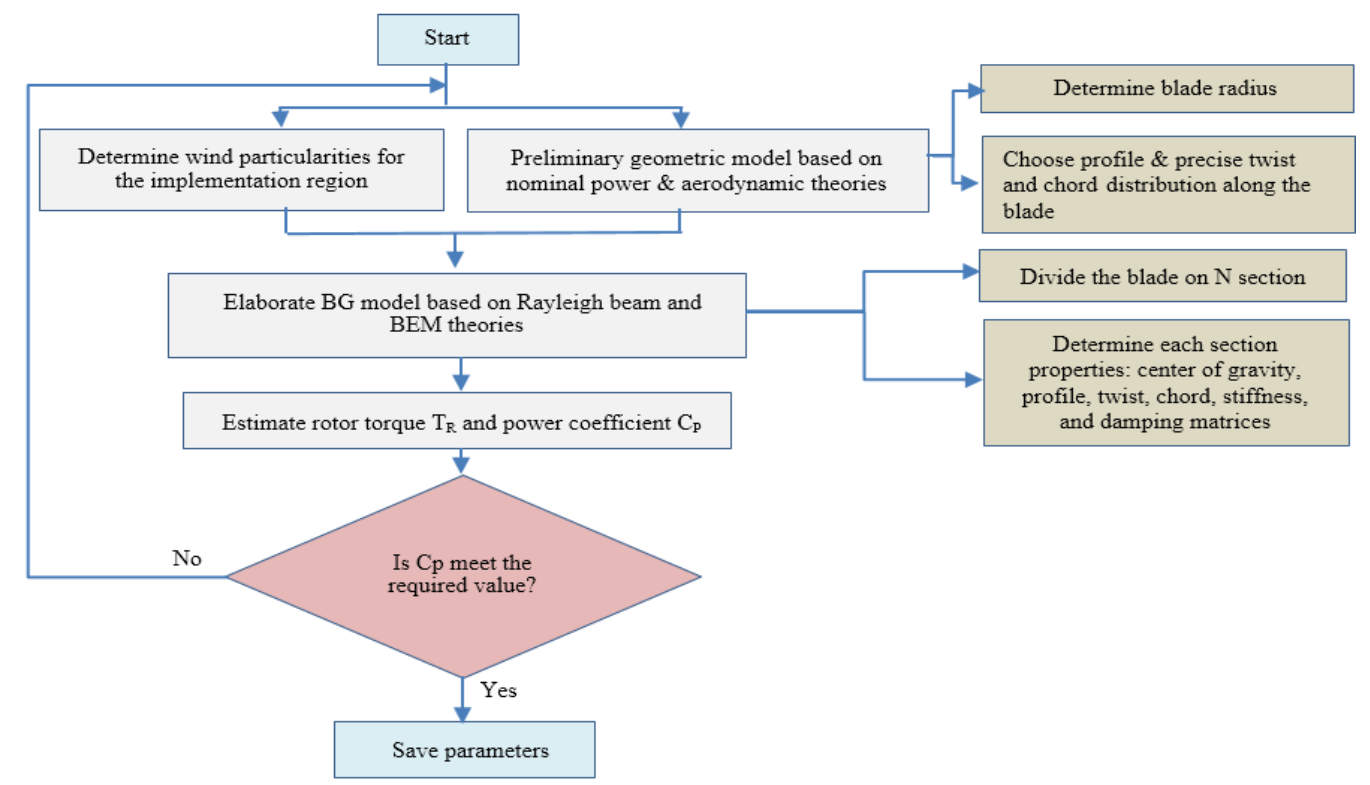

Figure 2. Flowchart of the proposed design optimization approach

\subsection{Bond Graph methodology}

Bond graph (BG) methodology for system modelling is based on the characterization of power exchange phenomena within a system $[10,11]$.BG is a powerful tool in modelling systems; especially in cases where subsystems of different physical character (mechanical, electrical, thermal, hydraulic ...) interact. The concept was introduced for the first time by Paynter in 1961 [12] and implicates the use of two energy variables: flow $\mathrm{f}(\mathrm{t})$ and efforts e (t), as shown in figure 2 (a). Each physical domain is associated to a type of flow and effort.

The adoption of a multi-discipline modeling tool is an asset in finding a good design solution. Thus, the use of BG formalism has increased significantly in last years; figure 2 (b) illustrates the evolution of using BG in recent researches according to Science Direct database for different research field. The significant use of this approach in multidisciplinary systems is due to its capacity to analyze the dynamic behavior of systems with high complexity.

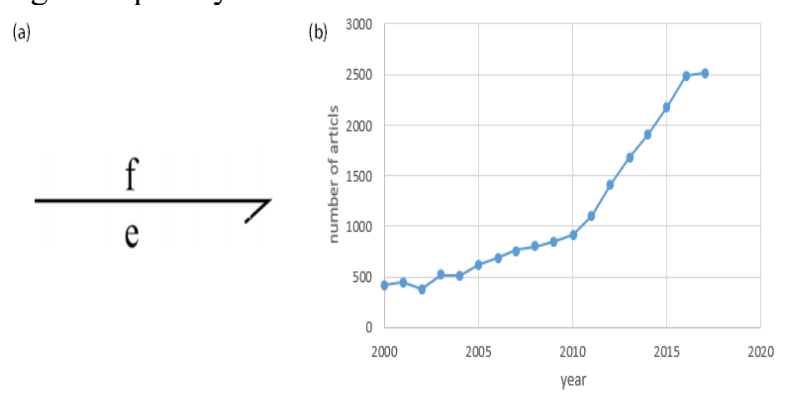

Figure 3. - (a) Link in a BG - (b) Evolution of Bond Graph use in recent researches

\subsection{An aided design approach based on BG for HAWT's rotor modeling}

The present work proposes a methodology for HAWT's rotor modeling in the design phase using $\mathrm{BG}$ methodology and aerodynamic theories. The flowchart of figure 2 resume basic steps on the proposed method. An application for $750 \mathrm{KW}$ HAWT's rotor is displayed in the next section.

\section{HAWT'S BLADE MODEL}

\subsection{GEOMETRIC \& BOND GRAPH MODEL}

In previous work [9], blade geometric model was performed based on a combination of the theories of axial flow and theory of blade member, then we looked for the NACA profile which provide the maximum blade efficiency compared to others. Herein, the parameters for a NACA 4415 are used to validate the proposed BG model. For aerodynamic efforts estimation, blade element momentum theory (BEM ) was used [13-14], detailed in next section. Figure 4 shows geometric parameters results.

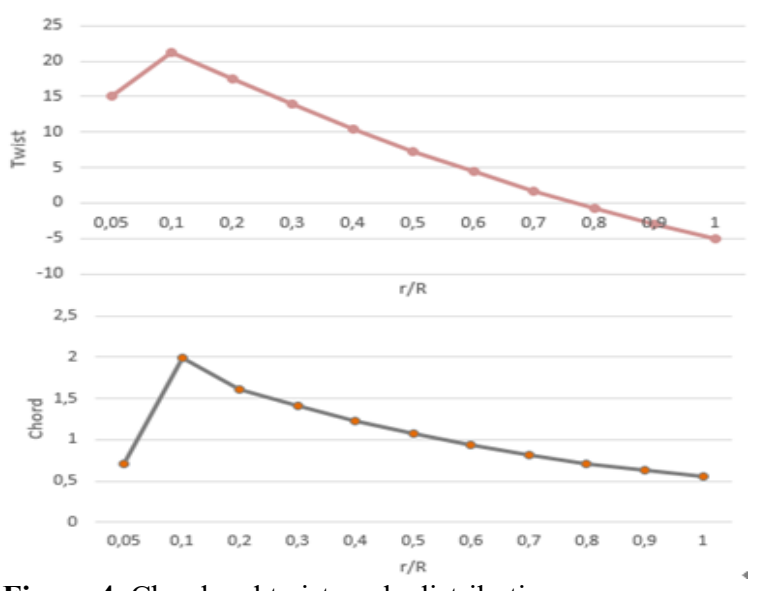

Figure 4. Chord and twist angle distribution 
As shown in figure 5 (a), each rotor's blade is composed by two different profiles with different length. The first part has a circular profile (in direct connection with the hub) and the rest has a NACA profile with different chord distribution. Other blade's configurations propose more than one profile along the blade to ensure maximum efficiency [15].

For blade modeling with BG, "Rayleigh beam theory" was used [8]. This consists on considering the blade as a beam divided into $\mathrm{N}$ sections, each of which is subjected to efforts created by wind flow (figure 5 (c)). The following equation gives the relation that links Newtonians forces and displacements in each blade section:

$$
\left[\begin{array}{c}
F_{\mathrm{i}} \\
M_{\mathrm{i}} \\
F_{\mathrm{i}+1} \\
M_{\mathrm{i}+2}
\end{array}\right]=\left[K_{i}\right]\left[\begin{array}{c}
y_{\mathrm{i}} \\
\theta_{i} \\
y_{i+1} \\
\theta_{\mathrm{i}+1}
\end{array}\right]
$$

The stiffness matrix depends on the length of the section $\mathrm{li}$ and on the flexural stiffness EI according to relation (3). Figure (6) shows blade BG model in case we take three sections. The first one with a circular profile and the others with NACA 4415 profile. Sf_bound $=0$ represents a rigid connexion with the hub. Figure (7) illustrate the proposed model linked to hub and gearbox.

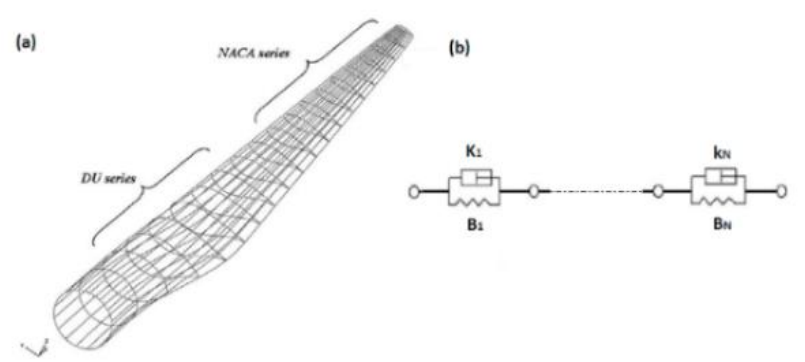

Figure 5. (a) Profile disposition along the blade (b) dynamic model by dividing the blade into $\mathrm{N}$ section (c) Newtonian efforts and displacements in a blade section

$$
\left[K_{i}\right]=\frac{8 E I}{\left(l_{i}+l_{i+1}\right)^{3}}\left[\begin{array}{cccc}
12 & 6\left(l_{i}+l_{i+1}\right) / 2 & -12 & 6\left(l_{i}+l_{i+1}\right) / 2 \\
6\left(l_{i}+l_{i+1}\right) / 2 & 4\left(l_{i}+l_{i+1}\right) / 2^{2} & -6\left(l_{i}+l_{i+1}\right) / 2 & 2\left(l_{i}+l_{i+1}\right) / 2^{2} \\
-12 & -6\left(l_{i}+l_{i+1}\right) / 2 & 12 & -6\left(l_{i}+l_{i+1}\right) / 2 \\
6\left(l_{i}+l_{i+1}\right) / 2 & 2\left(l_{i}+l_{i+1}\right) / 2^{2} & -6\left(l_{i}+l_{i+1}\right) / 2 & 4\left(l_{i}+l_{i+1}\right) / 2^{2}
\end{array}\right]
$$

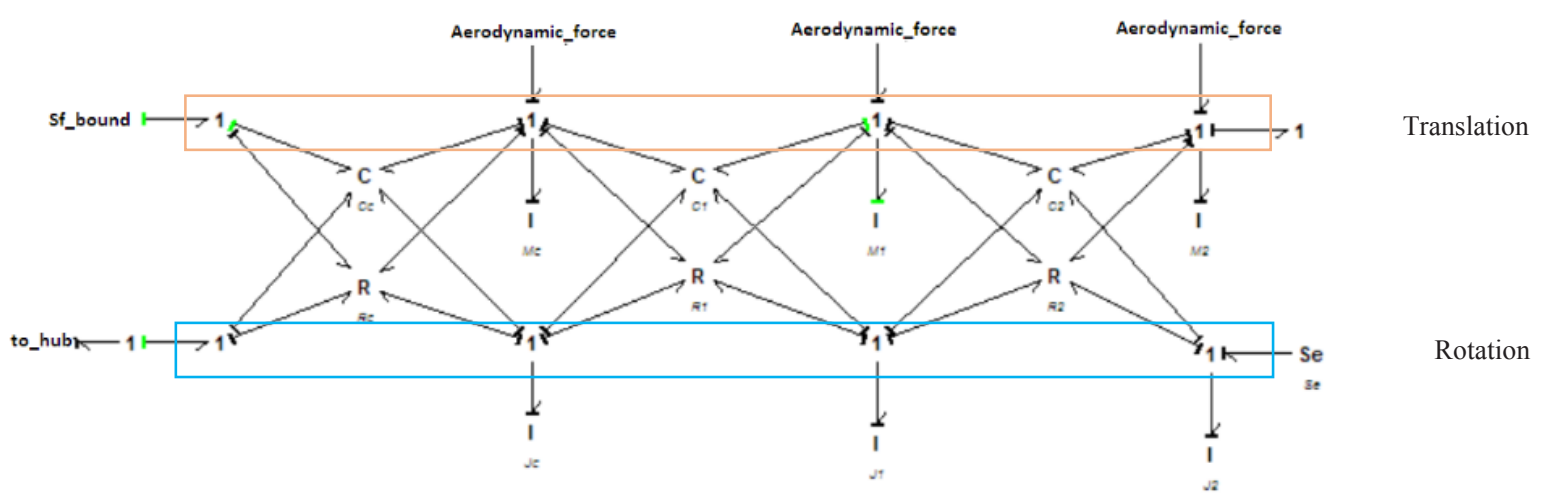

Figure 6. Blade model with three sections and two profiles

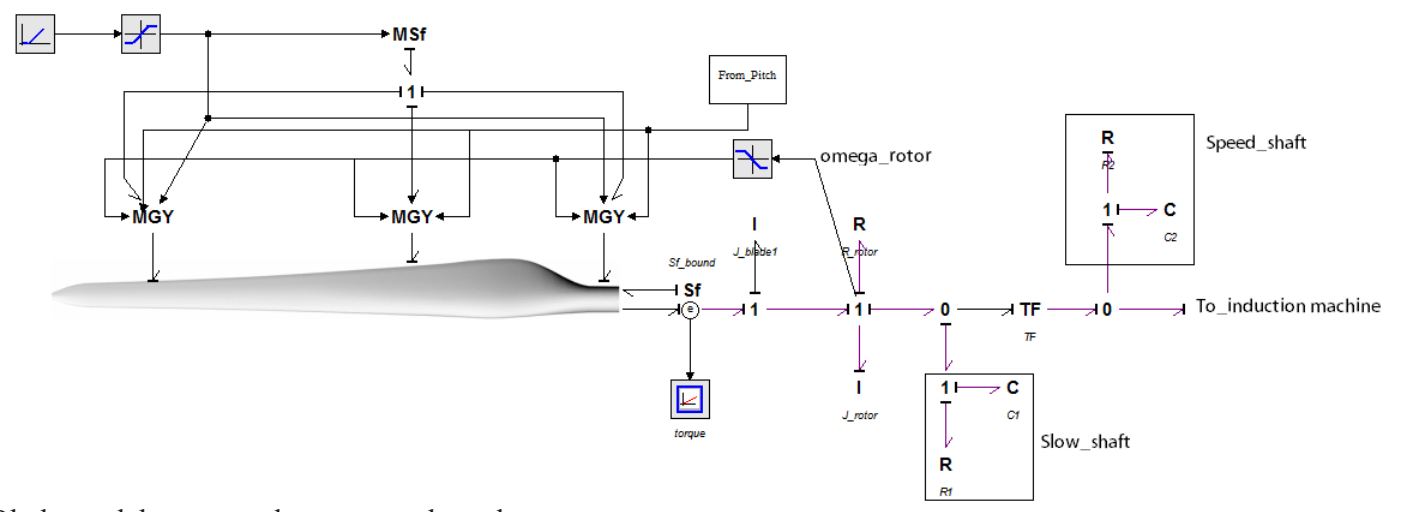

Figure 7. Blade model connected to rotor and gearbox 


\subsection{AERODYNAMIC MODEL}

Aerodynamic modeling of wind turbines is an essential step in the design of this machine. Its goal is to calculate the aerodynamic forces exerted on the blades to determine blade's optimal parameters and estimate the maximum power extracted by the rotor. This modeling is a complex task because of the rotation of the helix which creates a three-dimensional flow of air around the blades. The theory of BEM applied in this work is used in the calculation of aerodynamic forces acting on the wind turbine blades. This theory makes use of several parameters, in particular those related to the blade geometry and the used profile (figure 8).

The lift and drag forces can be resolved into axial and tangential components. The former is called axial thrust force and can be expressed as:

$$
\begin{aligned}
F_{t i} & =\left(\frac{1}{2} \rho V_{w} \frac{\left(1-a_{i}\right)^{2}}{\sin ^{2} \phi_{i}}\left(C_{l i} \sin \phi_{i}-C_{d i} \cos \phi_{i}\right) C_{i} l_{i}\right) V_{w} \\
& =M V_{\mathrm{W}}
\end{aligned}
$$

In equation (4), M represents the gyrator's modulus, which is used for the conversion of the wind energy into aerodynamic energy using modulated gyrator (MGY).

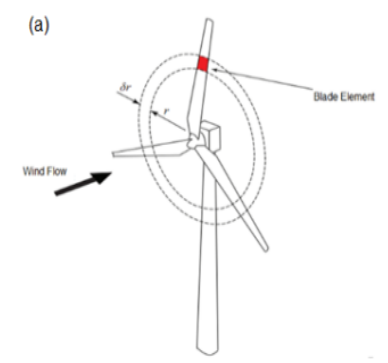

(b)

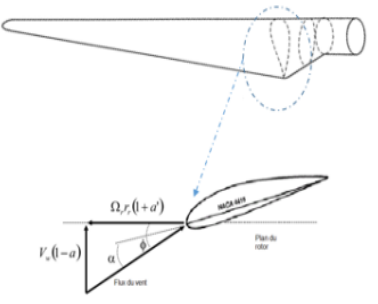

Figure 8. (a) Wind turbine rotor; (b) Projected velocities in the plane of the rotor

Both lift and drag forces contribute to the axial thrust force. Further, the lift force develops useful torque whereas the drag opposes it. Therefore, a high ratio $\mathrm{CL} / \mathrm{CD}$ is desired to achieve high conversion efficiency. Axial interference factor and tangential interference factor are calculated using mathematical code, based on BEM theory, for NACA4415 profile.

$$
\begin{gathered}
\text { With } \phi_{\mathrm{i}}=\tan ^{-1}\left(\frac{\mathrm{v}_{\mathrm{w}}\left(1-\mathrm{a}_{\mathrm{i}}\right)}{\Omega_{\mathrm{r}} \mathrm{r}_{\mathrm{i}}\left(1+\mathrm{a}_{\mathrm{i}}^{\prime}\right)}\right) \\
\mathbf{a}_{\mathrm{i}}=\left(1+\frac{4 \sin ^{2} \phi_{\mathrm{i}}}{\sigma_{\mathrm{i}}^{\prime}\left(\mathrm{C}_{\mathrm{li}} \cos \phi_{\mathrm{i}}+\mathrm{C}_{\mathrm{di}} \sin \phi_{\mathrm{i}}\right)}\right)^{-1} \\
\mathbf{a}_{\mathrm{i}}^{\prime}=\left(-1+\frac{4 \sin ^{2} \phi_{\mathrm{i}}}{\sigma_{\mathrm{i}}^{\prime}\left(\mathrm{C}_{\mathrm{li}} \cos \phi_{\mathrm{i}}-\mathrm{C}_{\mathrm{di}} \sin \phi_{\mathrm{i}}\right)}\right)^{-1}
\end{gathered}
$$

\section{RESULTS \& DISCUSSION}

In order to analyse dynamic responses of the proposed model, two different simulations were carried out. The first one is launched by introducing a constant wind speed. In the second one, variable wind was introduced using the assumption that wind speed never exceeds its higher limit which is $22 \mathrm{~m} / \mathrm{s}$, it allows the system to work without pitch control. Simulation results show an increase in power coefficient: $C_{\mathrm{P}} \approx 0.4147$ compared to [8] where $\mathrm{Cp}$ was about 0.33 , with $25,6 \%$ as difference percentage for the same HAWT rotor. The variable wind submodel is generated with random values $\epsilon[5 \mathrm{~m} / \mathrm{s}, 22 \mathrm{~m} / \mathrm{s}]$, this allows to test the model responses following a speed change in wind flow.

The system undergoes some oscillations in the beginning of the simulation due to the dynamic behaviors in the transient phase. The total useful torque developed by the turbine depends on a dimensionless coefficient CQ (figure 11) and it is expressed as:

For $\boldsymbol{\lambda}=5, \mathrm{VW}=9 \mathrm{~m} / \mathrm{s}$ and $\mathrm{Cp}=0.41$ as given below, we have $\operatorname{Tr}=139337$ N.m. This theoretical value matches the obtained one by model simulation, where $\mathrm{Tr}=3 * 42487=127461$ N.m with a gap of $\sim 8.5 \%$. It is mandatory to mention that the focus on this study is the blade geometric specificities. Therefore, if the pitch angle model and other wind turbine subsystems are added, the total useful torque will take its average limit.

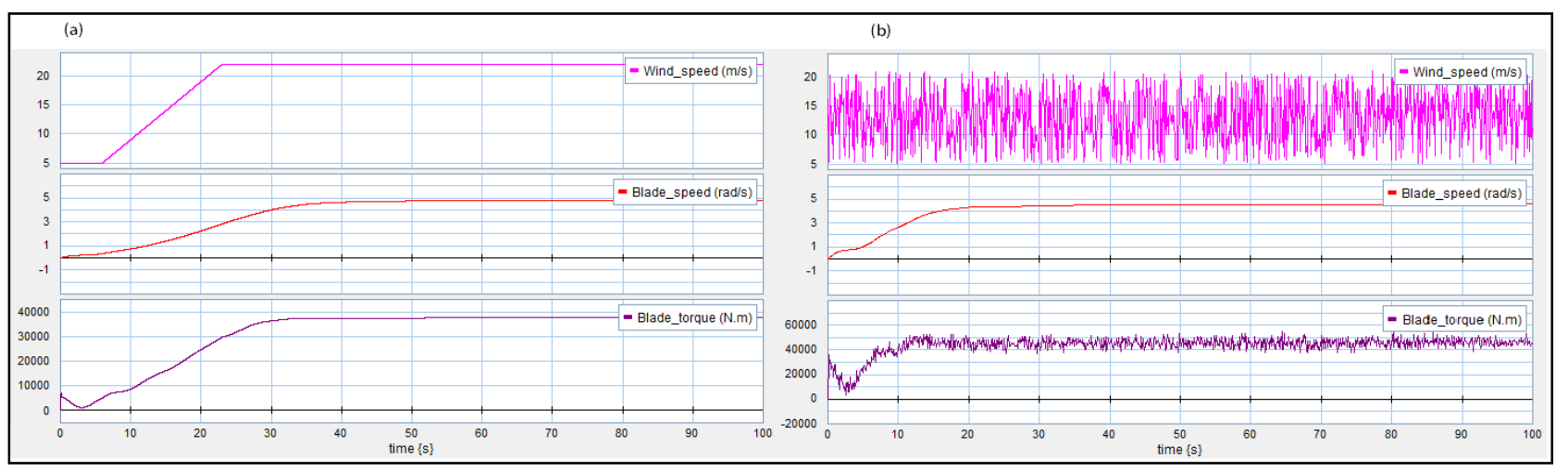

Figure 9. Simulation results (a) for constant wind and (b) variable wind speed 


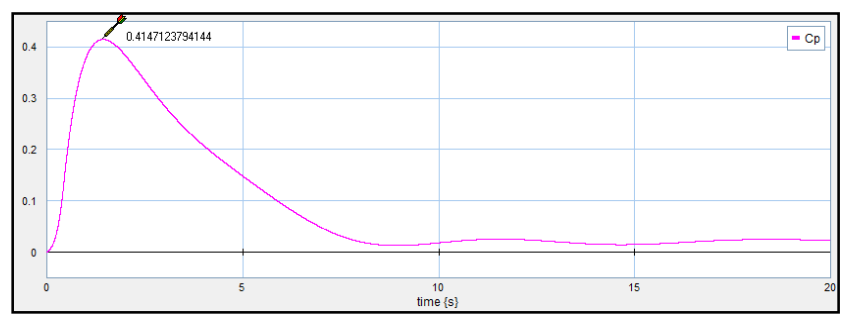

Figure 10. Power coefficient curve

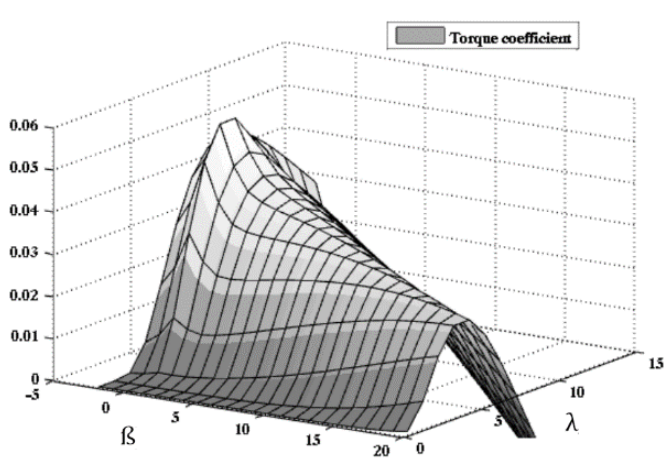

Figure 11. Torque coefficient as a function of pitch angle $\beta$ and tip speed ratio $\lambda$

\section{CONCLUSION}

Being a particular multidisciplinary system, a mechatronic approach for HAWT modeling is necessary. Thus, BG methodology is proposed as an innovative and versatile tool for the study of this system. The model realization using BG approach allows the estimation of several parameters facilitating the prediction of the system dynamic behavior and efficiency. Furthermore, the uses of this formalism are diversified to meet the different modeling needs such as optimization, generation of states equations, and determination of robust control laws by inverse $\mathrm{BG}$.

In this work, a model of wind turbine blades based on BG has been developed. The proposed model is based on several parameters combining the aerodynamic laws and the blades complex geometry. A rotor performance prediction for a $750 \mathrm{KW}$ wind turbine was made for two simulation cases: constant and variable wind speed. The steps of this study constitute a contribution to parameters design and optimization. Thus, it makes possible to estimate the variation effect of the geometrical features on the rotor response. Among these parameters, we mention the profile variation that was omitted in previous works.

In order to better predict the rotor responses, an extension of this study by adding other subsystems is envisaged in future papers. The important subsystem whose model must be detailed is the source of the system: the wind, which is characterized by its intermittency and its deterministic (wind shear, tower shadow) and stochastic parameters (rotational turbulence). On the other hand, an addition of pitch control model will increase the rotor efficiency by tracking the optimum angle of attack to reach and maintain the wind turbine nominal power.

TABLE I. NOMENCLATURE

\begin{tabular}{|c|c|c|c|c|c|}
\hline $\mathrm{a}$ & Axial interference factor & $\mathrm{C}_{\mathrm{Q}}$ & Torque coefficient & $\mathrm{R}$ & Blade radius \\
\hline $\mathrm{a}$ & Tangential interference factor & $\Omega$ & Rotor speed & $\mathrm{V}_{\mathrm{w}}$ & Air speed \\
\hline $\mathrm{Ci}$ & Section chord & $\mathrm{F}_{\mathrm{ti}}$ & Thrust force & $\mathrm{l}_{\mathrm{i}}$ & Section length \\
\hline $\mathrm{C}_{\mathrm{L}}$ & Lift coefficient & $\lambda$ & Specific speed (Tip speed ratio) & $\phi$ & flow angle \\
\hline $\mathrm{C}_{\mathrm{D}}$ & Optimum value of the drag coefficient & $\lambda_{\mathrm{r}}$ & Local specific speed & $\alpha$ & Incidence angle \\
\hline $\mathrm{C}_{\mathrm{P}}$ & power coefficient & $\mathrm{r}$ & Relative radius & $\beta$ & Optimal angle of twist \\
\hline
\end{tabular}

TABLE II. SIMULATION PARAMETERS

\begin{tabular}{|c|c|c|c|c|c|c|c|}
\hline \multicolumn{2}{|c|}{ Blade structure $\&$ aerodynamics } & \multirow{2}{*}{$\begin{array}{r}\text { Section } 1 \\
1.6\end{array}$} & \multirow{2}{*}{$\begin{array}{c}\text { Section } 2 \\
11.7\end{array}$} & \multirow{2}{*}{$\begin{array}{c}\text { Section } 3 \\
11.7\end{array}$} & \multicolumn{3}{|l|}{ Rotor } \\
\hline li & Section lenght (m) & & & & $\mathrm{E}$ & Young modulus $\left(\mathrm{N} / \mathrm{m}^{2}\right)$ & $17^{\mathrm{e}} 9$ \\
\hline $\mathrm{C}_{\mathrm{i}}$ & Chord (m) & 1 & 1.9 & 1 & $\mu$ & $\begin{array}{c}\text { Structural damping } \\
\text { coefficient }\end{array}$ & 0.01 \\
\hline$\beta_{\mathrm{i}}$ & Twist angle (deg) & 0 & 7.234 & 5.678 & $\mathrm{D}_{\text {hub }}$ & Main bearing $(\mathrm{N} / \mathrm{m})$ & 1000 \\
\hline $\mathrm{Z}_{\mathrm{i}}$ & $\begin{array}{l}\text { Center of gravity } \\
\text { position }(\mathrm{m})\end{array}$ & 0.8 & 7.5 & 18.3 & $\mathrm{~J}_{\text {hub }}$ & Hub inertia $\left(\mathrm{Kg} \cdot \mathrm{m}^{2}\right)$ & 5000 \\
\hline $\mathrm{I}_{\mathrm{i}}$ & $\begin{array}{c}\text { Moment of inertia } \\
\left(\mathrm{Kg} \cdot \mathrm{m}^{2}\right)\end{array}$ & $3 \mathrm{e} 10-5$ & $6 \mathrm{e} 10-5$ & $6 e 10-5$ & \multirow[t]{3}{*}{$\mathrm{R}$} & \multirow[t]{3}{*}{ Rotor Radius (m) } & \multirow[t]{3}{*}{22} \\
\hline Mi & Mass of section $(\mathrm{Kg})$ & 70 & 1000 & 450 & & & \\
\hline$\rho$ & Air density $\left(\mathrm{Kg} / \mathrm{m}^{3}\right)$ & & 1.225 & & & & \\
\hline
\end{tabular}




\section{References}

1. J. M. Jonkman, "Modeling of the UAE Wind Turbine for Refinement of FAST AD Modeling," 2003.

2. D. Afungchui, B. Kammoun, and A. Chauvin, "Development of a Wind Turbine Blade Profile Analysis Code Based on the Singularities Method," in Wind power, 2003, pp. 81-88.

3. R. Belamadi, A. Djemili, A. Ilinca, and R. Mdouki, "Aerodynamic performance analysis of slotted airfoils for application to wind turbine blades," J. Wind Eng. Ind. Aerodyn., vol. 151, pp. 79-99, 2016.

4. F. G. Jin Chen, Quan Wang, Shiqiang Zhang, Peter Eecen, "A new direct design method of wind turbine airfoils and wind tunnel experiment," Appl. Math. Model. ELSEVIER, vol. 40, pp. 2002-2014, 2015.

5. C. Thumthae, "Optimum Blade Profiles for a Variable-Speed Wind Turbine in Low Wind Area," Energy Procedia, vol. 75, pp. 651-657, 2015.

6. J. A. S. Witteveen, S. Sarkar, and H. Bijl, "Modeling physical uncertainties in dynamic stall induced fluidstructure interaction of turbine blades using arbitrary polynomial chaos," Comput. Struct., vol. 85, no. 1114, pp. 866-878, 2007.

7. G. AgarwalS, ChalalL, Dauphin-TanguyG, "Bond graph model of wind turbine blade.," Bond graph Model. Pract., 2012.
8. R. Sanchez and A. Medina, "Wind turbine model simulation: A bond graph approach," Simul. Model. Pract. Theory, vol. 41, pp. 28-45, 2014.

9. J. Naima, R. Mohammed, and Elf. Benaissa, "Threedimensional modeling of a horizontal axis wind turbine blade and profile effect analysis," in IEEE International renewbal and sustainbale energy conference, 2016, pp. 1-5.

10. Wolfgang Borutzky, Bond Graph modelling of engineering systems. springer, 2011.

11. Wolfgang Borutzky, Bond Graph methodology: Development and Analysis of Multi- disciplinary Dynamic System Models. Springer, 2010.

12. HM Paynter, "Analysis and design of engineering systems." The M.I.T. Press, Cambridge, 1961.

13. M. O. L. Hansen, Aerodynamics of Wind Turbines .

14. Z. Sun, J. Chen, W. Z. Shen, and W. J. Zhu, "Improved blade element momentum theory for wind turbine aerodynamic computations," Renew. Energy, vol. 96, pp. 824-831, 2016.

15. Y. J. Lee, Y. T. Jhan, and C. H. Chung, "Fluidstructure interaction of FRP wind turbine blades under aerodynamic effect," Compos. Part B Eng., vol. 43, no. 5, pp. 2180-2191, 2012. 